\title{
Author Spotlight: Rahul S. Dalal
}

\author{
Rahul S. Dalal $^{1}$
}

Accepted: 12 January 2021 / Published online: 29 January 2021

(c) The Author(s), under exclusive licence to Springer Science+Business Media, LLC part of Springer Nature 2021

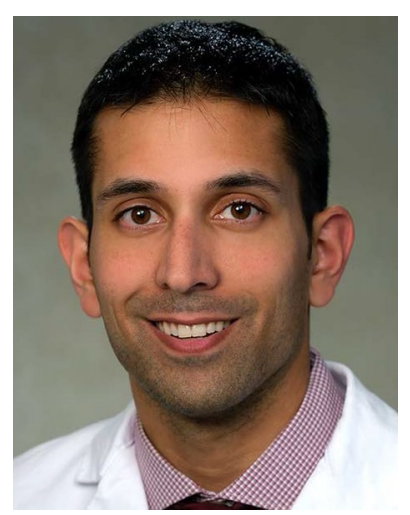

Rahul Dalal, MD, is a clinical and research fellow in gastroenterology at Brigham and Women's Hospital and Harvard Medical School. He completed his undergraduate degree at Yale University, medical degree at Brown University, and internal medicine residency at the University of Pennsylvania. His clinical interests are in inflammatory bowel diseases (IBD), and his research focuses on prediction of IBD complications, comparative effectiveness of biologic agents, and dose optimization of medical therapies for moderate-severe IBD. He received the Fellows in Training Award in IBD from the American College of Gastroenterology in 2020 for his work on ustekinumab dose intensification in Crohn's disease. Rahul will stay at Brigham and Women's Hospital to complete an advanced IBD fellowship during the 2022-2023 academic year.

Publisher's Note Springer Nature remains neutral with regard to jurisdictional claims in published maps and institutional affiliations.

Rahul S. Dalal

rsdalal@bwh.harvard.edu

1 Division of Gastroenterology, Hepatology and Endoscopy, Department of Medicine, Brigham and Women's Hospital, Harvard Medical School, Boston, MA, USA 